\title{
Modulation of Rat Cancer-Induced Bone Pain is Independent of Spinal Microglia Activity
}

\author{
Marta Diaz-delCastillo *,+® ${ }^{*}$, Rie Bager Hansen ${ }^{\dagger}$, Camilla Kristine Appel, Lykke Nielsen, \\ Sascha Nolsøe Nielsen, Konstantinos Karyniotakis, Louise M. Dahl, Rikke B. Andreasen and \\ Anne-Marie Heegaard \\ Department of Drug Design and Pharmacology, University of Copenhagen, DK-2100 Copenhagen, Denmark; \\ rikkerie.hansen@sund.ku.dk (R.B.H.); camilla.k.appel@gmail.com (C.K.A.); lykkenielsen93@gmail.com (L.N.); \\ saschanolsoe@hotmail.com (S.N.N.); k.karyniotakis@gmail.com (K.K.); louisedah192@gmail.com (L.M.D.); \\ rbandreasen@hotmail.com (R.B.A.); amhe@sund.ku.dk (A.-M.H.) \\ * Correspondence: marta.castillo@sund.ku.dk; Tel.: +45-71832607 \\ + These authors have contributed equally to this manuscript.
}

Received: 16 July 2020; Accepted: 21 September 2020; Published: 24 September 2020

check for updates

Simple Summary: Cancer-induced bone pain is one of the most debilitating and feared symptoms of cancer patients. Many patients have inadequate pain relief with the current treatment options, and there is a need for new pain medication targeting the mechanisms of cancer-induced bone pain. It has been hypothesized that microglia (cells involved in central nervous system homeostasis) are involved in the signalling of cancer-induced bone pain; however, data from animal models are inconsistent. Here, we apply immunohistochemical staining of the microglial markers ionizing calcium-binding adaptor molecule 1 (Iba-1) and phosphorylated p38-mitogen-activated protein kinase (P-p38 MAPK) to show that microglial reaction is not a feature of cancer-induced bone pain; this independently of disease stage, animal sex or cancer cell-line. Furthermore, pharmacological inhibition of microglia did not affect pain-related behaviours in cancer-bearing rats. Overall, our data support that microglial reaction is not a main player in cancer-induced bone pain.

\begin{abstract}
The dissemination of cancer to bone can cause significant cancer-induced bone pain (CIBP), severely impairing the patient's quality of life. Several rodent models have been developed to explore the nociceptive mechanisms of CIBP, including intratibial inoculation of breast carcinoma cells in syngeneic Sprague Dawley rats. Using this model, we investigated whether resident spinal microglial cells are involved in the transmission and modulation of CIBP, a long-debated disease feature. Immunohistochemical staining of ionizing calcium-binding adaptor molecule 1 (Iba-1) and phosphorylated p38-mitogen-activated protein kinase (P-p38 MAPK) showed no spinal microglial reaction in cancer-bearing rats, independently of disease stage, sex, or carcinoma cell line. As a positive control, significant upregulation of both Iba-1 and P-p38 was observed in a rat model of neuropathic pain. Additionally, intrathecal administration of the microglial inhibitor minocycline did not ameliorate pain-like behaviors in cancer-bearing rats, in contrast to spinal morphine administration. Our results indicate that microglial reaction is not a main player in CIBP, adding to the debate that even within the same models of CIBP, significant variations are seen in disease features considered potential drug targets. We suggest that this heterogeneity may reflect the clinical landscape, underscoring the need for understanding the translational value of CIBP models.
\end{abstract}

Keywords: cancer-induced bone pain; microglia; spinal cord; animal models 


\section{Introduction}

The dissemination of cancer to bone can lead to significant pain, with up to $85 \%$ of patients experiencing cancer-induced bone pain (CIBP) [1-3]. The patient with CIBP typically presents with a somewhat steady background pain and, as the disease progresses, breakthrough pain episodes, which are transient, severe pain exacerbations [4-6]. That said, the patient's pain experiences are heterogeneous and there may be differences in the underlying pathology requiring different treatment strategies $[7,8]$.

CIBP is particularly difficult to relieve with the available analgesic therapies $[9,10]$, and there is an apparent need for novel therapeutic approaches to handle both background and breakthrough pain. Drug development is guided by the promise of targets, but, as many analgesic drug trials fail [11], it may be time to reconsider whether the models developed for CIBP are exploited in the best possible way when translating the results into the clinic [12-14].

To better understand the mechanisms underlying CIBP, several rat and mouse models have been developed over the last three decades. The most commonly used involve the inoculation of syngeneic carcinoma cell lines in the intramedullary cavity of a long bone (e.g., tibia or femur), leading to the localized development of osteolytic bone lesions and pain-like behaviors [15-17]. These models have been useful to advance our knowledge of CIBP, demonstrating that this pain type shares nociceptive and neuropathic pain components but also presents with its own characteristics and neurochemical signature [18-20].

Microglia are a diverse population of resident macrophage-like cells in the central nervous system (CNS) that play a crucial role in tissue homeostasis. First described in 1975 [21], their role in pain has become increasingly studied. Under physiological conditions, microglia survey the neuronal tissue with their ramified processes and play a crucial role in maintaining CNS health by engulfing and pruning superfluous synapses and eliminating dead cells, protein aggregates, and other damaging residues in the brain and spinal cord [22]. Upon nerve injury, microglial cells become reactive and hypertrophic and their number in the dorsal horn of the spinal cord increases, a process termed microgliosis [23]. Reactive microglia release interleukins and other factors that, in turn, stimulate immune cells and spinal neurons, ultimately contributing to the transmission of the pathological nociceptive signal [24]. While microglial involvement in rodent models of neuropathic pain is well established [23,25], it remains controversial whether microglial reaction is a main feature of CIBP and, in essence, whether this is a drug target that should be pursued.

Here, we investigated whether microglial reaction plays a central role in pain transmission in the commonly used Walker 256 breast cancer model of CIBP. Through immunohistochemical characterization of ionizing calcium-binding adaptor molecule 1 (Iba-1) and phosphorylated p38-mitogen-activated protein kinase (P-p38 MAPK), two markers of microglial reaction [25], and through pharmacological microglial inhibition our findings suggest that microglial reaction is not a main feature of this model of CIBP; this is independently of disease stage, rat sex, and cancer cell line inoculated. However, instead of dismissing microglia as a possible target, we suggest that these diverse features can be exploited to reflect the heterogeneity of the patient population. Thus, further characterization of the models is crucial to understand their potential translational validity.

\section{Results}

\subsection{Intratibial Inoculation of Walker 256 Cancer Cells Causes Cancer-Induced Bone Pain in Female Rats}

The Walker 256 rat model was used to investigate whether microglia are involved in the nociceptive transmission of CIBP (Figure 1A). Cancer-bearing rats displayed pain-related behaviors, measured as a decrease in limb-use score and weight-bearing ratio at post-surgical day $10\left(F_{1,8}=196.00, p<0.01\right.$ for limb use; $F_{2,16}=43.52, p<0.0001$ for weight bearing; $\mathrm{n}=5$; Figure 1B,C). Moreover, cancer cell inoculation led to the development of osteolytic bone lesions, measured as a significant decrease in the relative bone density of cancer-bearing tibias, compared with sham $\left(F_{1,8}=19.73, p<0.01 ; n=5\right.$; Figure 1D). 
A
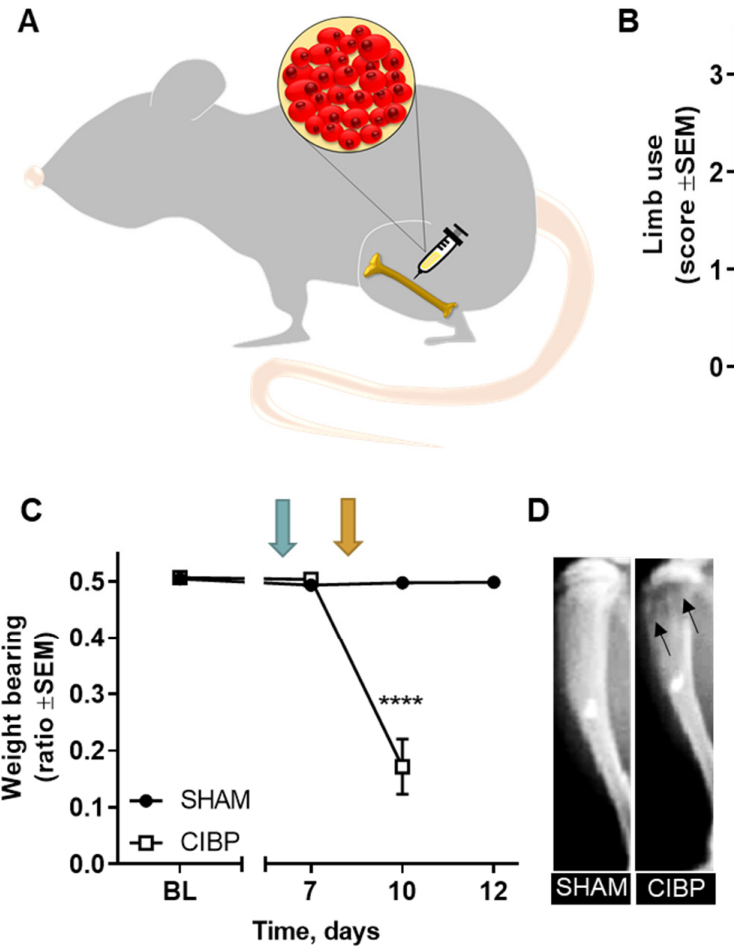

B

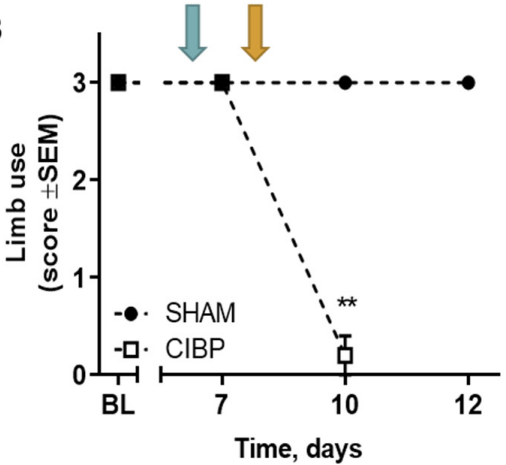

E

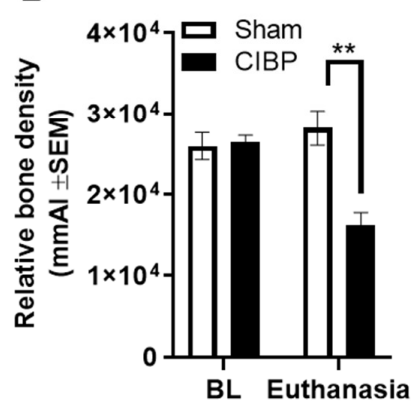

Figure 1. The Walker 256 rat model of cancer-induced bone pain (CIBP). (A) A rat model of CIBP was set up through intratibial inoculation of $10^{5}$ Walker 256 breast carcinoma cells in female Sprague Dawley rats. (B,C) Cancer-bearing rats presented significantly lower limb-use scores (B) and weight-bearing ratios (C) at post-surgical day 10, compared with sham. (D) Representative X-ray images displaying a sham tibia (left) and a cancer-bearing tibia (right) and endpoint. Arrows indicate areas of bone degradation. (E) Intratibial cancer cell inoculation led to a significantly lower relative bone density in cancer-bearing tibias compared with baseline; no changes in relative bone density were observed in sham tibias. (B,C). Blue arrows indicate the time point just before the development of pain-like behaviors (post-surgical day 6) and orange arrows illustrate the early stage of CIBP, where the pain-like behaviors initiate (post-surgical day 8). Sham $n=5 ; \operatorname{CIBP} n=5 . \mathrm{BL}=$ baseline. Data are presented as mean \pm standard error of the mean (SEM). ${ }^{* *} p<0.01 ;{ }^{* * * *} p<0.0001$.

\subsection{Absence of Microglial Reaction in the Ipsilateral Dorsal Horn of Female Rats Inoculated with Walker} 256 Cancer Cells

Temporal microglial reaction has been described to be involved in different phases of CIBP, either at the early or late stages of disease progression; however, the findings are ambiguous, with reports of microglial reaction being important for the initiation of CIBP but not its maintenace, and vice versa [26,27]. Thus, we examined whether microglial reaction is present just before the development of measureable nociception (post-surgical day 6), in the initial phase of the nociceptive phenotype (post-surgical day 8), and in the progressed stage of CIBP (defined as the humane end point, at limb-use score 0).

Immunohistological analyses of the dorsal horn of the spinal cord revealed a lack of significant differences in the numbers of $\mathrm{Iba}-1^{+}$or $\mathrm{P}-\mathrm{p} 38^{+}$cells between the ipsilateral and contralateral dorsal horn of cancer-bearing or sham rats, as well as between the ipsilateral dorsal horns of cancer-bearing and sham rats, both at post-surgical days 6 and 8 (day 6: $F_{1,18}=3.57, p>0.05$; day 8: $F_{1,18}=5.54$, $p>0.05 ; \mathrm{n}=5-6$; Figure 2B,C). Interestingly, a trend toward increased Iba-1 and P-p38 cells was observed on post-surgical day 6 , but not on day 8 ; this trend toward microglial reaction could be related to post-surgical nociception [28]. In the progressed stage of CIBP, no significant difference was found in the number of spinal Iba- $1^{+}$cells between the ipsilateral and contralateral dorsal horn of cancer-bearing or sham rats. Likewise, no significant difference was found in the number of Iba- $1^{+}$cells in the ipsilateral dorsal horn of cancer-bearing rats, compared with sham $\left(F_{1,16}=2.45, p>0.05 ; \mathrm{n}=5\right.$, 
Figure 3), demonstrating that even in the late stages of CIBP, we did not detect microglial reaction in female rats innoculated with Walker 256 cancer cells.

A

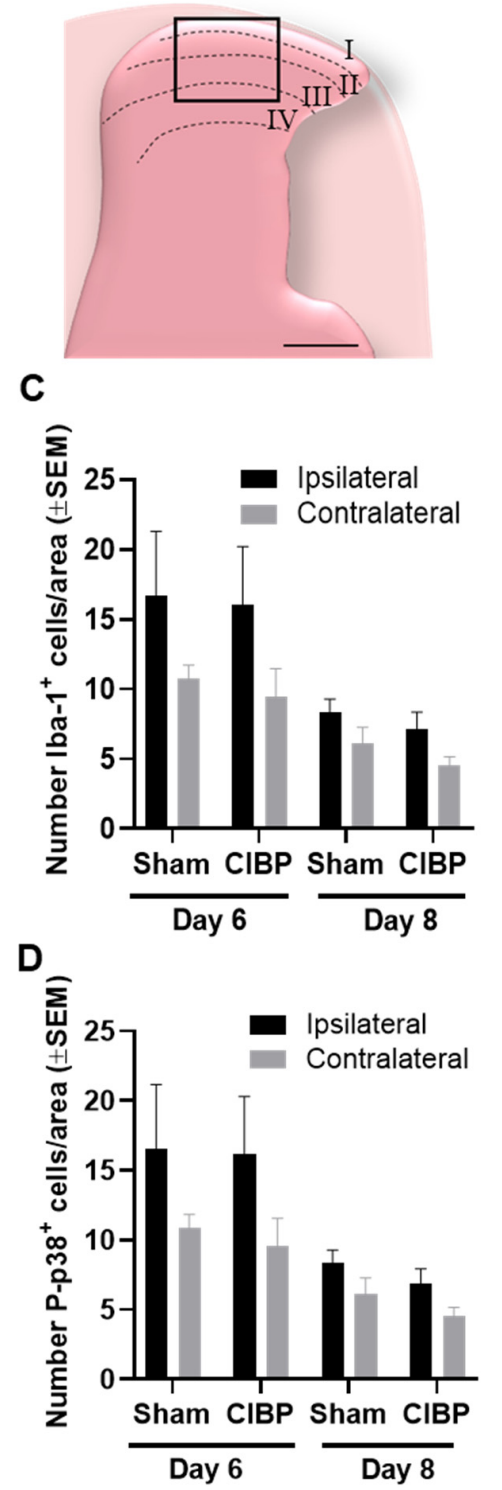

B

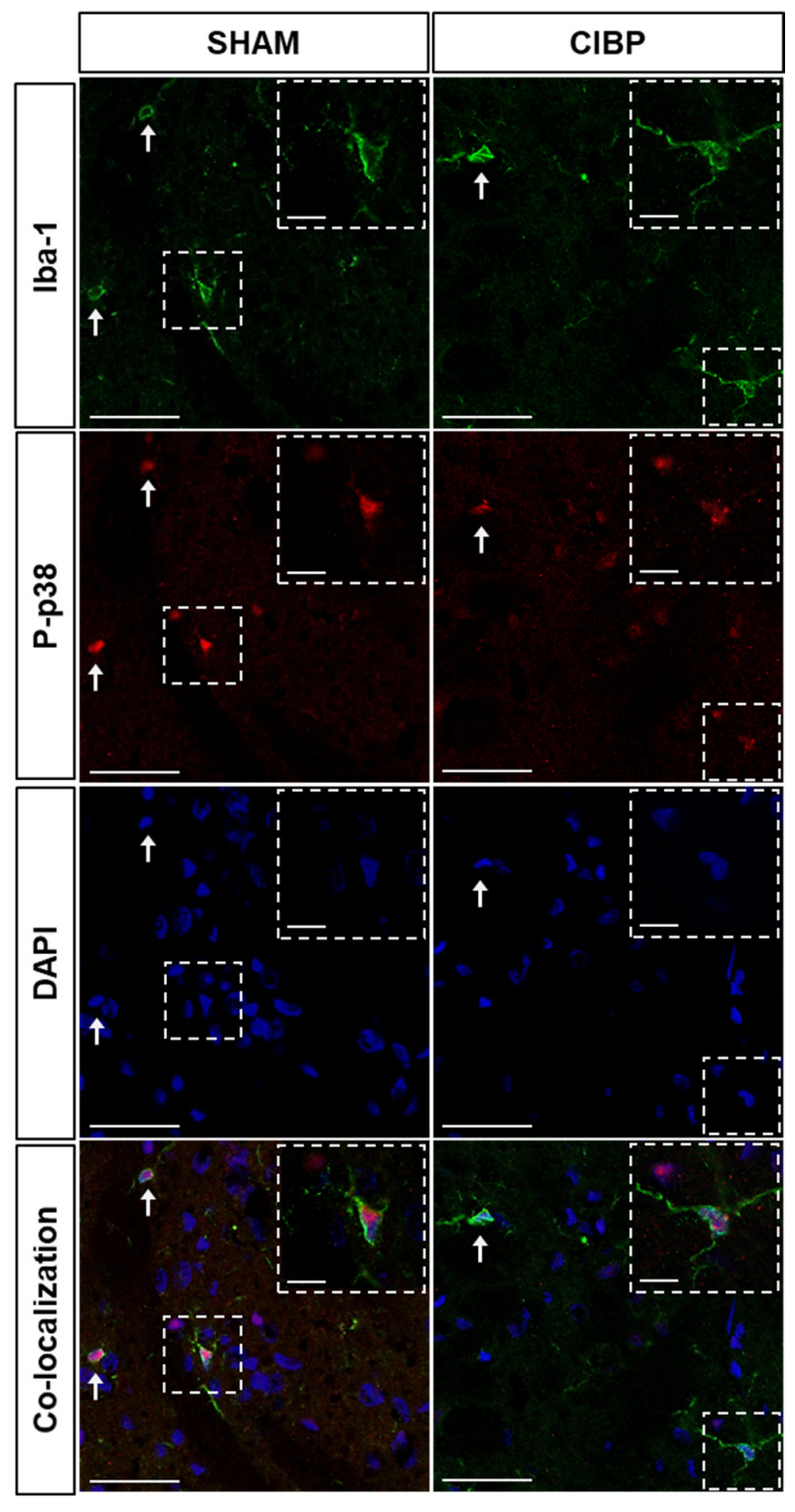

Figure 2. Immunohistochemical characterization of microglial reaction in the female Walker 256 model of CIBP. (A) Diagram demonstrating the area of the spinal cord dorsal horn used for analysis $\left(347 \times 260 \mu \mathrm{m}^{2}\right)$. Scale bar indicates $250 \mu \mathrm{m}$. (B) Representative confocal images of microglia characterization (Iba-1, P-p38, DAPI, and co-localization) in the lumbar spinal cord of sham and cancer-bearing rats. Arrows indicate Iba- $1^{+}, \mathrm{P}-\mathrm{p} 38^{+}$, and DAPI ${ }^{+}$cells. Arrows indicate examples of microglia cells expressing Iba- $1^{+}$, P-p38, and $\mathrm{DAPI}^{+}$. Images were obtained with a $40 \times$ objective lens, scale bars indicate $50 \mu \mathrm{m}$, and scale bars in the inserts indicate $10 \mu \mathrm{m}$. (C) The number of Iba- $1^{+}$cells was not significantly higher in the ipsilateral dorsal horn of the spinal cord of cancer-bearing rats, compared with the contralateral side and with sham rats on post-surgical days 6 or 8 . (D) The number of P-p38 ${ }^{+}$cells did not significantly differ between the ipsilateral and contralateral dorsal horns, nor between the ipsilateral dorsal horns of cancer-bearing and sham rats on post-surgical days 6 or 8 . For each time point: Sham $n=5$, CIBP $n=6$. Data are presented as mean \pm SEM. 


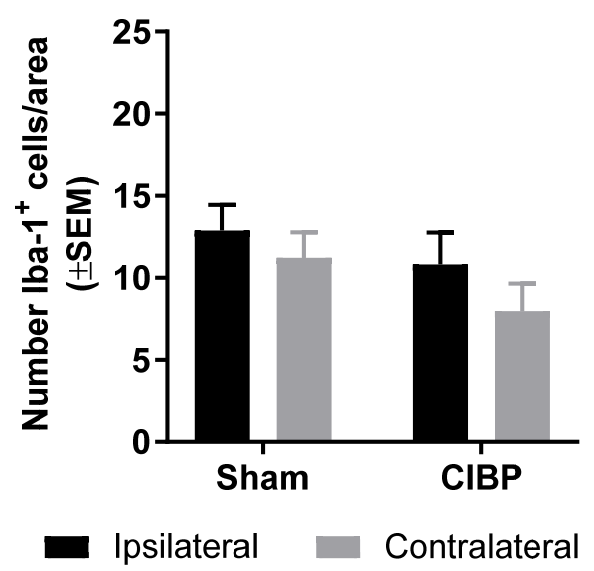

Figure 3. Advanced CIBP in females did not induce spinal microglial reaction. The number of Iba- $1^{+}$ cells was not significantly higher in the ipsilateral dorsal horn of the spinal cord of female cancer-bearing rats, compared with sham, at the humane endpoint (limb-use score of 0 ). The number of Iba- $1^{+}$cells was not significantly different between the ipsilateral and contralateral dorsal horns of cancer-bearing or sham rats. Sham $n=5, \operatorname{CIBP} n=5$. Data are presented as mean \pm SEM.

\subsection{Absence of Microglial Reaction Is Independent of Cancer Cell Line Inoculated}

To evaluate whether the observed lack of microglial reaction in this CIBP rat model was exclusive to the inoculation of Walker 256 breast carcinoma cells, independent experiments were performed where Sprague Dawley rats were inoculated with the syngeneic MRMT-1 breast carcinoma cell line and compared to Sprague Dawley rats inoculated with the Walker 256 cell line. No significant differences were observed in the numbers of Iba- $1^{+}$cells in the ipsilateral dorsal horn in either group of cancer-bearing rats compared with the ipsilateral horn of sham rats $\left(F_{2,40}=5.23, p>0.05 ; \mathrm{n}=6-10\right.$; Figure 4). Also, neither of the models showed a significant increase in the number of Iba- $1^{+}$cells in the ipsilateral dorsal horn compared with the contralateral dorsal horn $\left(F_{1,40}=13.12, p>0.05 ; \mathrm{n}=6-10\right.$; Figure 4$)$. Both Walker 256- and MRMT-1-inoculated rats developed significant pain-related behaviors and osteolytic lesions over time, confirming disease phenotype development (Supplementary Materials Figure S1).

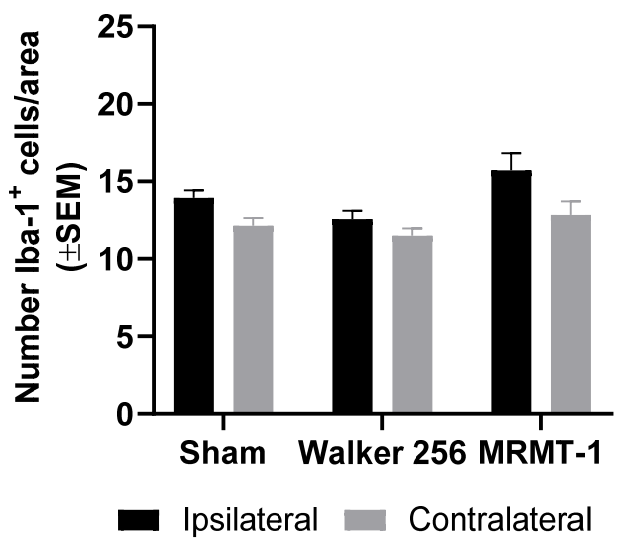

Figure 4. CIBP does not induced microglial reaction in two different CIBP rat models. Intratibial inoculation of MRMT- 1 or Walker 256 carcinoma cells did not cause a significant upregulation of Iba- $1^{+}$ cells in the ipsilateral dorsal horn of the spinal cord of cancer-bearing rats compared with sham. Sham $\mathrm{n}=10$; Walker $256 \mathrm{n}=7$; MRMT-1 $\mathrm{n}=6$. Data are presented as mean \pm SEM. 


\subsection{Absence of Microglial Reaction in Male Rats Inoculated with Walker 256 Cancer Cells}

Sexual dimorphism in microglial reaction has previously been described in rodent models of chronic neuropathic pain $[27,29]$. While most studies investigating the role of spinal microglia in the Walker 256 model of CIBP focus on females [26,30-32], we also addressed whether microglial reaction was present in cancer-bearing male rats. No significant difference was found in the number of $\mathrm{Iba}-1^{+}$ cells between the ipsilateral dorsal horn of cancer-bearing and sham rats $\left(F_{1,24}=0.55, p>0.05 ; \mathrm{n}=6-8\right.$; Figure 5A), indicating a lack of microglial reaction. A small but significant increase of Iba-1+ cells was found in the ipsilateral dorsal horn of cancer-inoculated rats when compared to the contralateral site $\left(F_{1,24}=6.86, p<0.01 ; \mathrm{n}=6-8\right.$; Figure 5A). The lack of microglial reaction was further supported by the absence of significant differences in P-p38 expression among groups, demonstrating that microglial reaction is also absent in the male Walker 256 model of $\operatorname{CIBP}\left(F_{1,24}=8.95, p>0.05 ; \mathrm{n}=6-8\right.$; Figure 5B). As expected, innoculation of Walker 256 cancer cells in male Sprague Dawely rats led to the development of pain-like behaviors over time, as well as a decrease in relative bone density (Figure S2).

A

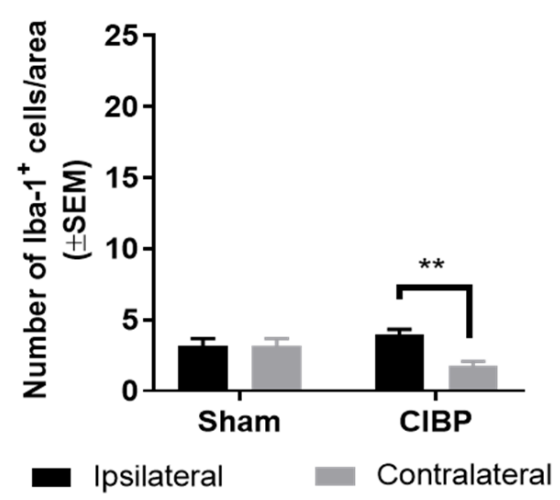

B

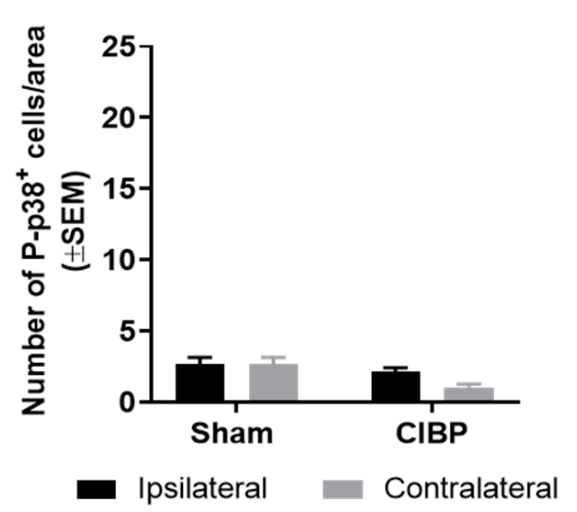

Figure 5. CIBP did not induce microglial reaction in male rats. (A) No significant difference was found in the number of spinal Iba- $1^{+}$cells between the ipsilateral dorsal horn of cancer-bearing and sham rats $(p>0.05)$. Cancer-bearing rats showed a significant increase in the number of Iba- $1^{+}$cells in the ipsilateral dorsal horn of the spinal cord compared with the contralateral dorsal horn. (B) No significant differences were detected in the numbers of P-p38 $8^{+}$cells within or among groups. Sham $n=6$, CIBP $n=8$. ** $p<0.01$. Data are presented as mean \pm SEM.

\subsection{Microglial Reaction Is Observed in the Spinal Cord of Rats with Spared Nerve Injury}

To demonstrate the robustness of our method to detect Iba-1 and P-p38 upregulation, a rat model of neuropathic pain was established. Male rats underwent the spared nerve injury (SNI; Figure 6A) where the common peroneal and tibial branches of the sciatic nerve are sectioned. This leads to the development of mechanical hyperalgesia on the lateral side of the operated hind paw. In the von Frey test, the SNI-operated rats showed a significantly lower paw withdrawal threshold from post-surgical day 3 when compared with sham rats $\left(F_{3,33}=5.83, p<0.05\right.$ on days 3 and $10, p<0.001$ on day 7 ; $\mathrm{n}=6-7$; Figure $6 \mathrm{~B})$.

Lumbar (L4) spinal sections from sham and SNI-operated rats were visualized by confocal microscopy to confirm microglia morphology and co-localization of P-p38 with microglia cells. Microglia in sham rats appeared with fine, ramified processes, while microglia in SNI-operated rats had the more amoboid appearance characteristic of microglia reaction (Figure 7A). On average, $97.7 \%$ of P-p3 $8^{+}$cells were found to also express Iba- 1 in the the ipsilateral dorsal horn of SNI-opereated rats (range of P-p38 ${ }^{+}$and $\mathrm{DAPI}^{+}$cells counted: $45-86$, range of P-p38 ${ }^{+}, \mathrm{Iba}^{+}{ }^{+}$, and $\mathrm{DAPI}^{+}$cells counted $44-83, \mathrm{n}=3)$. 
A

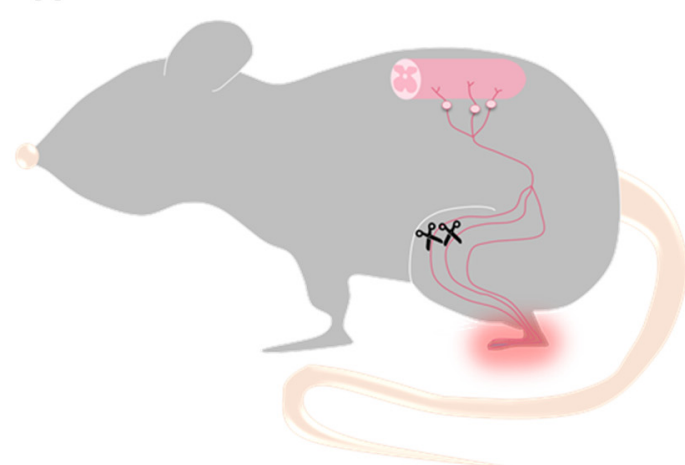

B

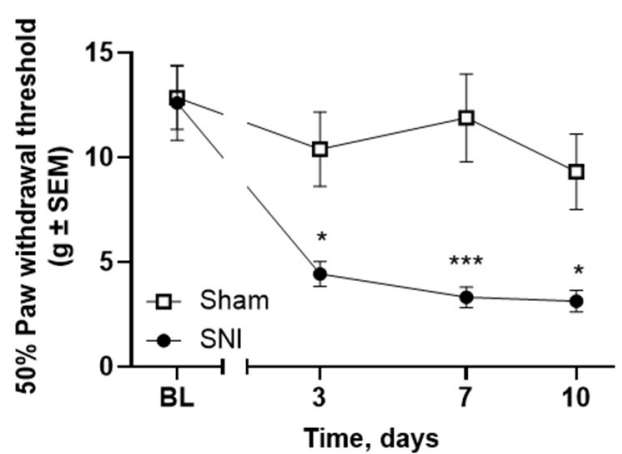

Figure 6. The spared nerve injury (SNI) rat model. (A) The SNI rat model of neuropathic pain was established through surgical sectioning of the common peroneal and tibial branches of the sciatic nerve. (B) SNI-operated rats presented a significantly lower mechanical threshold from post-surgical day 3. Sham $\mathrm{n}=6$, SNI $\mathrm{n}=7$. Data are presented as mean \pm SEM. ${ }^{*} p<0.05 ;{ }^{* * *} p<0.001$.

As SNI male rats presented pronounced mechanical hyperalgesia at post-surgical day 7, the spinal cords of male naïve, sham, and SNI Sprague Dawley rats were collected 7 days after surgery for immunohistological characterization of the expression of Iba-1 and P-p38. As expected, SNI rats showed significant microglial reaction in the ipsilateral dorsal horn compared to the ipsilateral dorsal horn of both sham and naïve rats $\left(F_{2,18}=33.79\right.$, Iba-1: $p<0.0001$, P-p38: $p<0.01$; Iba-1: $p<0.0001$, P-p38: $p<0.001$, respectively; $\mathrm{n}=3-5$; Figure 7A-C). Moreover, a significant upregulation of Iba- $1^{+}$ and P-p38 ${ }^{+}$cells was found in the ipsilateral dorsal horn of the SNI-operated rats compared with the contralateral dorsal horn $\left(F_{1,18}=11.02\right.$, Iba-1: $p<0.001$, P-p38: $p<0.05 ; \mathrm{n}=5$; Figure 7A-C). No significant differences were found between the ipsilateral and contralateral dorsal horn of naïve or sham rats or between the ipsilateral side of naïve and sham rats $(n=3-5$; Figure $7 A-C)$.

\subsection{Pharmacological Inhibition of Spinal Microglia Does not Ameliorate Nociception in the CIBP Rat Model}

To further confirm that microglial reaction is not a main feature of the Walker 256 model of CIBP, we investigated whether pharmacological inhibition of spinal microglia had an anti-nociceptive effect. Female Sprague Dawley rats inoculated with Walker 256 cancer cells developed pain-related behaviors over time, seen as a pronounced decrease in limb-use scores from post-surgical day 8 (Figure 8A). Upon reaching a limb-use score of 1 , rats were randomized to receive a single intrathecal dose of the microglial inhibitor minocycline $(100 \mu \mathrm{g})$, morphine $(10 \mu \mathrm{g})$, or vehicle. Intrathecal administration of $100 \mu \mathrm{g}$ minocycline had no effect on the observed pain-related behavior as compared with vehicle (Figure 8C,D). In contrast, intrathecal administration of $10 \mu \mathrm{g}$ morphine caused a significant amelioration of pain-related behaviors in cancer-bearing rats compared with vehicle, seen as a significant increase in the limb-use score and weight-bearing ratio $\left(F_{12,90}=2.73, p<0.05\right.$ and $F_{12,90}=0.57, p<0.05$, respectively; $n=6$; Figure $8 C, D)$. Importantly, at euthanasia the relative bone density of the ipsilateral tibias did not differ between groups, indicating a similar extent of osteolytic lesions $\left(F_{2,30}=0.13\right.$, $p>0.05 ; \mathrm{n}=6$; Figure 8B). Within groups, a significant difference was seen in the relative bone density comparing the ipsilateral and contralateral tibias $\left(F_{1,30}=202.20, p<0.0001\right.$ ipsilateral vs. contralateral; $\mathrm{n}=6$; Figure $8 \mathrm{~B})$. 
A

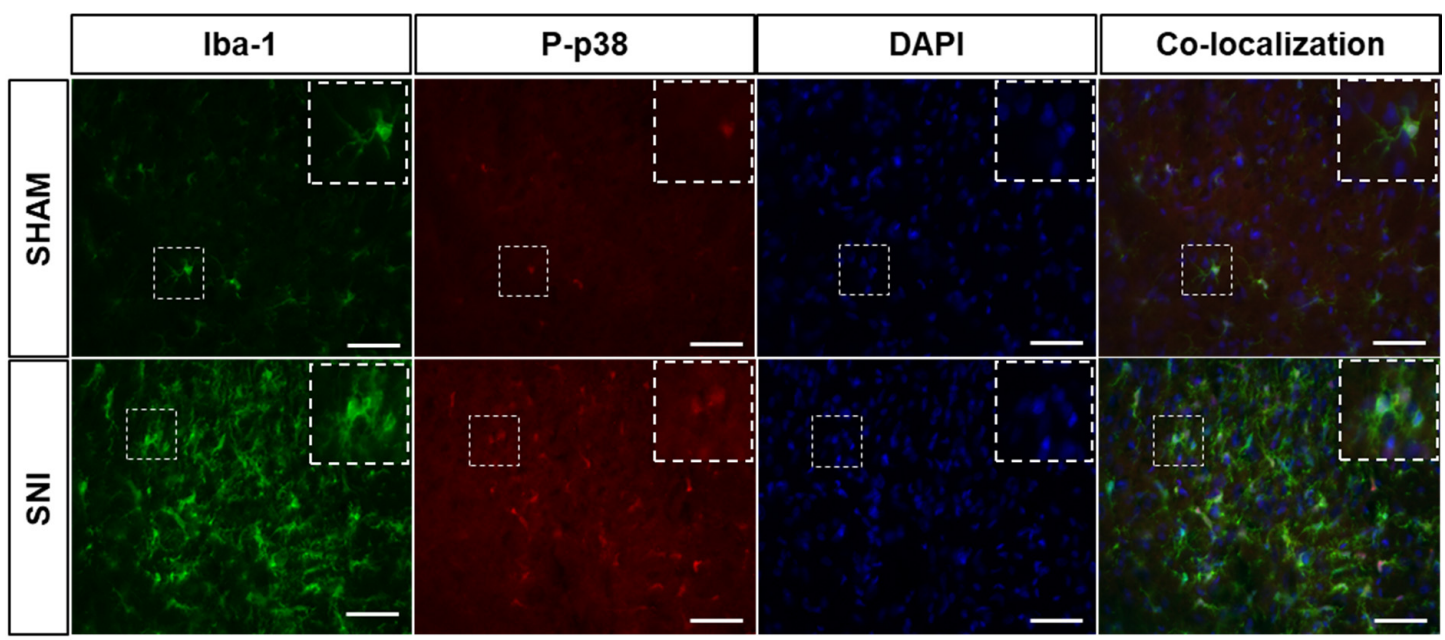

B

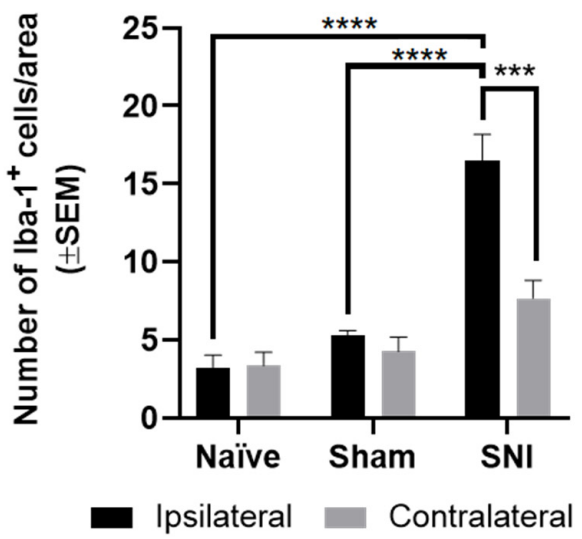

C

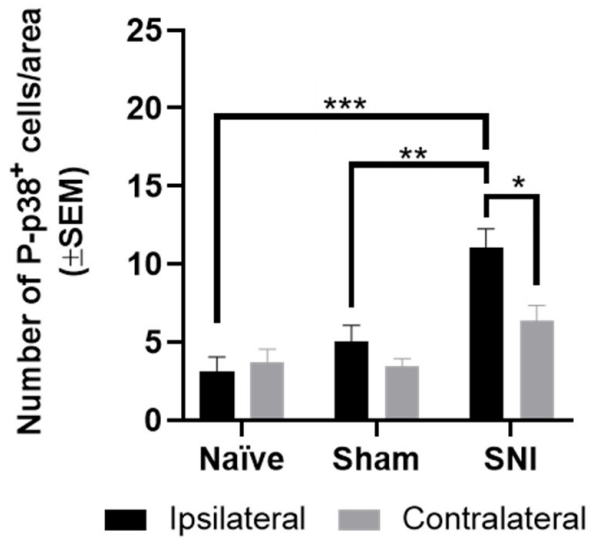

Figure 7. Immunohistochemical characterization of microglial reaction in the SNI model. (A) Representative confocal microscopy images of microglia characterization (Iba-1 and P-p38) in the lumbar spinal cord of sham and SNI-operated rats. Co-localization of Iba-1 and P-p38 was estimated as $97.7 \%(n=3)$. Note that the microglia depictured in the insert of SNI-operated rats demonstrate two P-p38+ and Iba-1+ microglia and a microglia only positive for Iba-1. Images were obtained with a $40 \times$ objective lense, and scale bars indicate $50 \mu \mathrm{m}$. (B) The ipsilateral dorsal horn of SNI-operated rats presented a significantly higher number of Iba- $1^{+}$cells compared with contralateral side, and with the ipsilateral dorsal horn of naïve and sham rats. (C) The ipsilateral dorsal horn of the lumbar spinal cord of SNI-operated rats presented a significant upregulation in the number of P-p38 ${ }^{+}$cells compared with the contralateral side and with the ipsilateral dorsal horn of naïve and sham rats. (B,C) Naïve $\mathrm{n}=3$, sham $\mathrm{n}=4$, SNI $\mathrm{n}=5$. Data are presented as mean \pm SEM. ${ }^{*} p<0.05 ;{ }^{* *} p<0.01 ;{ }^{* * *} p<0.001$; $* * * * p<0.0001$. 
A

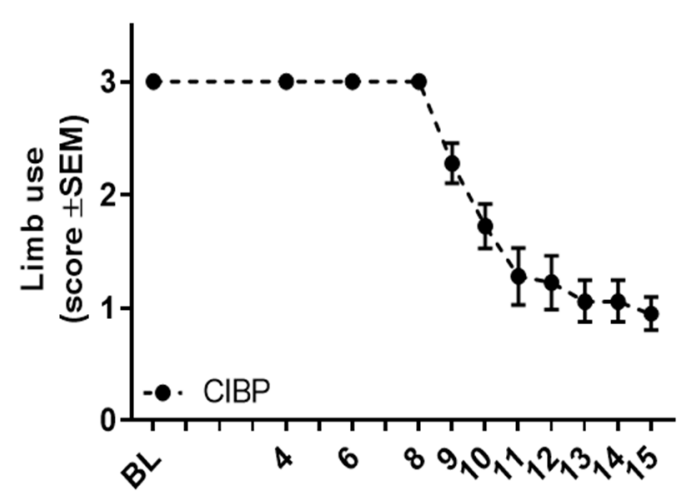

C
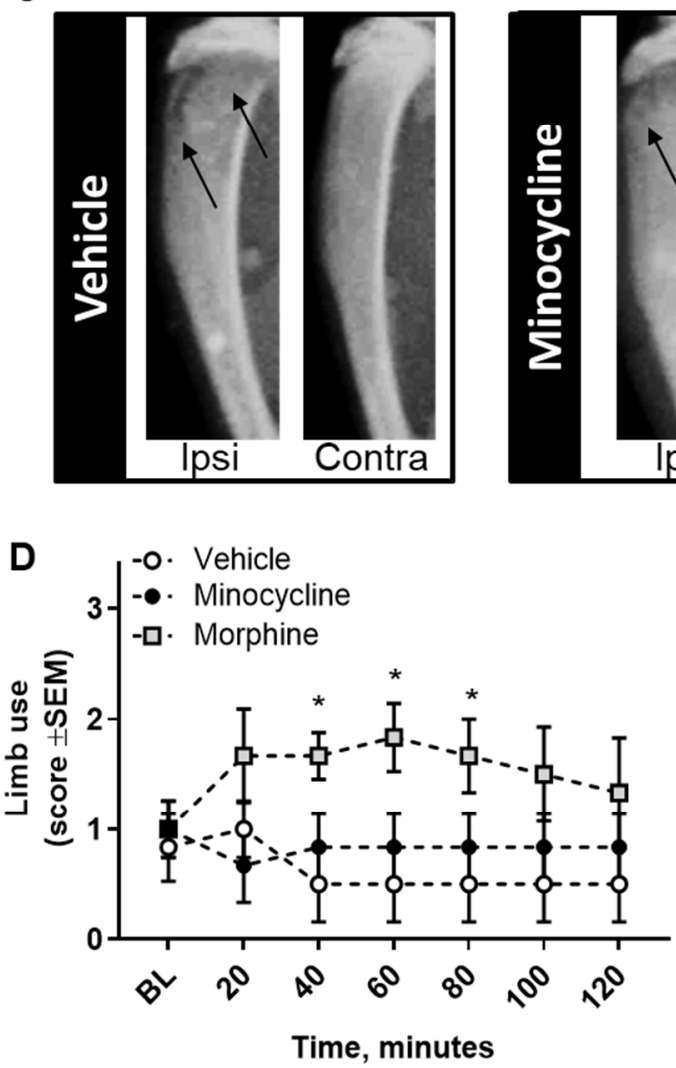

\section{B}
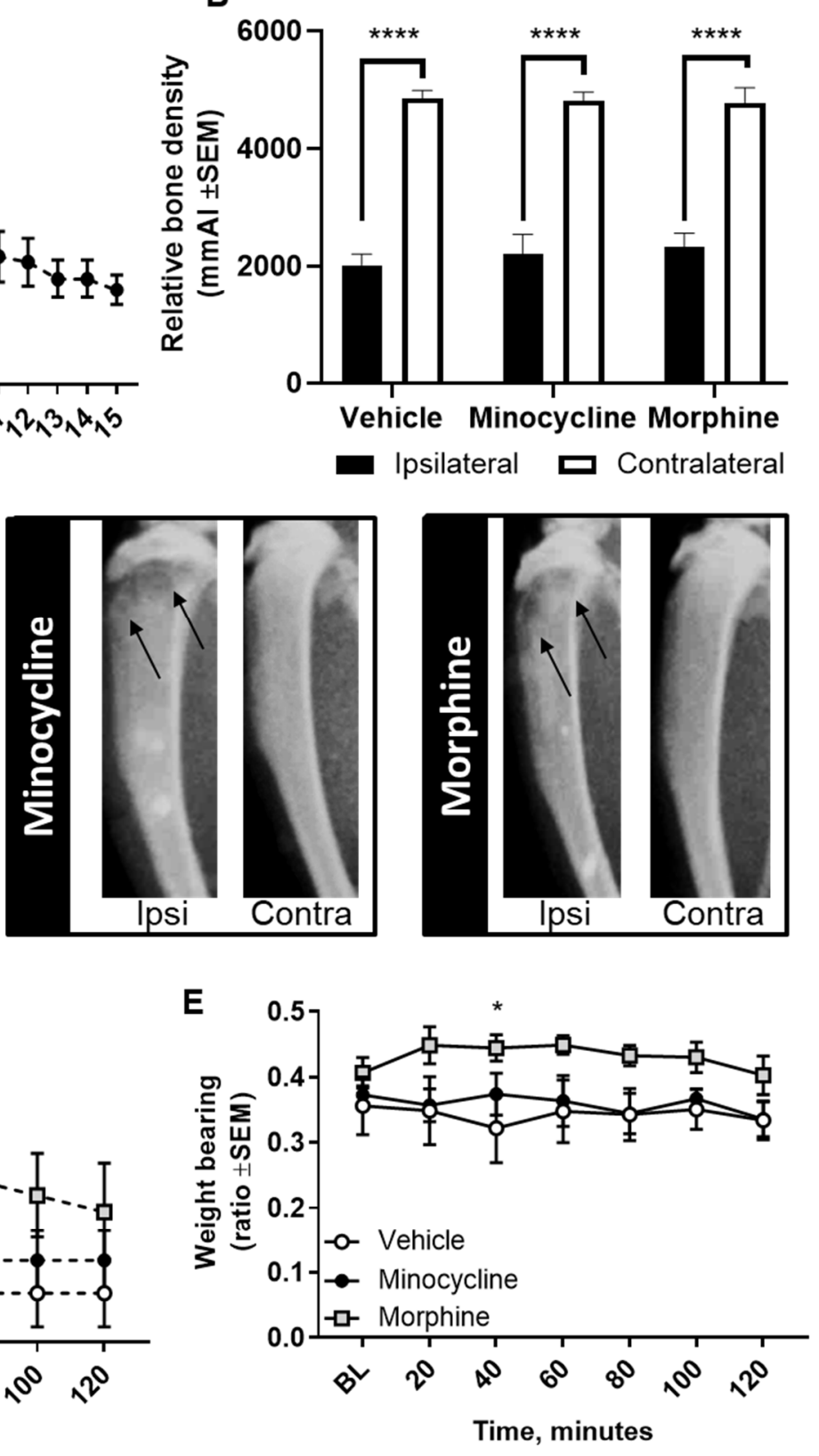

Figure 8. Pharmacological glial modulation in the CIBP model. (A) Cancer-bearing rats developed a pain-like phenotype from post-surgical day 8 . Upon reaching a limb-use score of 1 , rats receive an intrathecal (i.t.) injection of minocycline $(100 \mu \mathrm{g})$ or morphine $(10 \mu \mathrm{g})$ and their behavior was assessed at 20-min intervals during $2 \mathrm{~h}$. (B) At euthanasia, the relative bone density of ipsilateral cancer-bearing tibias was significantly lower than the contralateral tibia in all experimental groups. (C) Representative images of the ipsilateral and contralateral tibias of cancer-bearing rats receiving a single intrathecal administration of vehicle, minocycline, or morphine. Arrows indicate areas of bone degradation. (D) Spinal administration of minocycline did not alter limb-use scores, while morphine administration induced anti-nociception 40 to $80 \mathrm{~min}$ after administration. (E) Similarly to the limb-use test, intrathecal minocycline did not alter the weight-bearing ratio, but spinal morphine administration caused a significant increase $40 \mathrm{~min}$ after administration and showed a positive trend $60 \mathrm{~min}$ after administration $(p=0.0574)$. (B-E) Vehicle-treated $n=6$; minocycline-treated $\mathrm{n}=6$; morphine-treated $\mathrm{n}=6 .{ }^{*} p<0.05 ;{ }^{* * * *} p<0.0001$. Data are presented as mean \pm SEM. BL: baseline. 


\section{Discussion}

Bone is the preferred metastatic site for prevalent cancers, such as breast and prostate cancer [33] and metastatic bone disease can be very painful and difficult to treat with the available analgesics [9]. While increasing efforts are being made to identify new analgesics for the treatment of chronic pain conditions, most promising targets lack translational value and fail in the early stages of clinical trials, suggesting that a better characterization of the animal models is needed [12,13]. In models of painful bone metastases, a recurrent debate is whether spinal microglia are involved in the transmission of CIBP, with contradictory data being reported [20,26,30-32,34-36]. Our results suggest that microgliosis is not a main feature of CIBP, independent of disease stage, cancer cell line, or sex of the rat. In accordance, acute intrathecal administration of the microglial inhibitor minocycline failed to attenuate pain-like behaviors in cancer-bearing female rats.

To better understand the role of spinal microglia in CIBP, we used the female Walker 256 model in which Walker 256 carcinoma cells were intratibially inoculated in syngeneic Sprague Dawley rats, a model of CIBP in which microgliosis is commonly described [26,30-32]. We applied immunohistochemistry to investigate the expression of Iba-1 and P-p38 MAPK, two markers used to detect microglial reaction [25], and saw no increase in the numbers of spinal Iba- $1^{+}$or P-p38 ${ }^{+}$cells in cancer-bearing rats. While our results are contradictory to many of the reported observations, they are in agreement with other published data $[35,37]$.

The p38 is one of three major members of the MAPK family, the others being extracellular signal-regulated kinase (ERK) and c-Jun N-terminal kinase (JNK). The p38 is a global downstream signaling kinase present in many CNS cell types, but, interestingly, the phosphorylated version (P-p38) is in many pain models found to be primarily activated in microglia and barely found in neurons, astrocytes, or oligodendrocytes [38-45]. This was first observed in models of peripheral neuropathic pain $[39,40,45]$ but has also been seen a various time points in cancer-induced bone pain [44], in the development of tolerance to morphine analgesia [41], and after intrathecal injection of lipopolysaccharide (LPS) [42]. In agreement with these findings, we observed that about $97 \%$ of P-p38+ cells were also positive for Iba-1 in the ipsilateral spinal cord dorsal horn of SNI-operated rats. Therefore, P-p38 was used as an additional marker of microglia reaction. The immunohistochemical analysis was performed at the lumbar spinal cord segmental level 4 (L4), as robust microglia reaction previously has been demonstrated in that area in the Walker 256 model of CIBP [26,37,44,46-50].

Complicating the debate on the role of microglia in the transmission of the nociceptive signal, temporal activation of microglia has been observed in several pain models, including models of CIPB $[26,31,32,34]$, in which the findings are again contradictory. It has thus been reported that microglia are important for the initiation of CIBP, but not its maintenance [26,32], as opposite to that microglia are important for the maintenance of CIBP, but not the initiation [30] and also that microglia are involved in both phases [31]. To further explore this, we investigated microglial reaction in the early and late phases of CIBP, but found no significant increase in the numbers of Iba- $1^{+}$or P-p $38^{+}$cells just before the initiation of nociception (post-surgical day 6), as the nociceptive-phenotype commenced (post-surgical day 8), or at the progressed stage, where the humane endpoint was reached. Thus, we did not observe a temporal microglial reaction in the Walker 256 model of CIBP.

Sexual dimorphism in microglial reaction has also been described, and it has been suggested that pathological microglia signaling is fundamentally different between male and female rodents in models of peripheral neuropathic pain $[27,29]$. This is in contrast to CIBP, where microglial reaction is reported in both male and female cancer-bearing rodents [26,30,32,36,48,51]. In our study, we found no indication of microglial reaction in either female or male rats inoculated with Walker 256 cancer cells, again adding to the evidence that microglial reaction is not a uniform feature over the same models of CIBP. 
The occurrence of microglial reaction is likely affected by the choice of cancer cell line, animal species, and strain. In this study, we inoculated male Sprague Dawley rats with the two syngeneic Walker 256 and MRMT-1 breast carcinoma cell lines and found no microglial reaction in either model. In a model of secondary brain tumors, Walker 256 cells obtained from two different cell banks (American Type Culture Collection (ATCC) and Cell Resource Centre for Medical Research at Tohoku University (CRTCU)) showed differences in microglial reaction, with the inoculation of the ATCC cell line inducing widespread, ill-defined labelling throughout the brain tumor mass and the CRTCU cell line showing sparse but specific, discrete labelling [52]. These results indicate that even the choice of cell line origin may influence the development of microgliosis. Moreover, both mouse and rat models of CIBP show contradictory findings on microglial reaction $[20,26,30-32,34-36]$ and it has been reported, for models of neuropathic and inflammatory pain, that Sprague Dawley rats purchased from different vendors show profound differences in the nociceptive hypersensitivity and response to analgesics [53]. Together, these findings suggest that the cancer cell line, the animal, and most likely the interaction between the two can influence whether microglia play a role in chronic CIBP.

The identification of new targets guides drug discovery, and it is crucial that our preclinical models have high translational validity [54]. The animal models of CIBP are generally considered appropriate, as good face and predictive validity have been demonstrated, i.e., the animal models present with tumor burden, bone resorption or formation, and pain-like behaviors that can be attenuated with drugs known to alleviate pain in patients, such as morphine [55,56]. In the Walker 256 model of CIBP, we observed the expected anti-nociceptive effect following acute spinal administration of morphine. To modulate microglia pharmacologically, we evaluated the effect of intrathecal administration of minocycline in cancer-bearing rats. In agreement with the lack of microglial reaction, minocycline did not cause any alteration of the pain-like phenotype of cancer-bearing rats. While single intrathecal administration of minocycline has previously been reported as anti-nociceptive in this model [30,46,57], repeated dosing may be necessary to attenuate CIBP. There is only little evidence of the involvement of microglia in human pain states and, so far, most clinical trials of microglia modulatory agents have not had robust or consistent results [58-61]. A trial using minocycline suggested that perioperative administration decreased persistent pain after lumbar discectomy in a subgroup of patients presenting with deep spontaneous pain at baseline [58], and a small effect was found in a study of lumbar radicular neuropathic pain [59]. The lack of more pronounced effects may be due to the heterogeneity of the patient population, which may be reflected in the animal models.

Taken together, our preclinical data suggest that microglial reaction is not a main feature of CIBP. Additional evaluation of spinal cytokine levels, protein expression, or RNA analyses of spinal tissue could help further elucidate this discrepancy between models of CIBP. However, as reports on the role of microglial in the transmission of CIBP are conflicting, it could be speculated that microglia-targeting treatments are beneficial for a subset of patients with painful metastatic bone disease; however, this would need to be confirmed in the clinical setting.

\section{Materials and Methods}

\subsection{Cell Culture}

Walker 256 cells (Rikken Cell Bank, Ibaraki, Japan) were cultured in Roswell Park Memorial Institute (RPMI) medium without phenol red, supplemented with $10 \%$ Fetal Bovine Serum (FBS) and $1 \%$ penicillin-streptomycin-glutamine. Cells were routinely cultured at $37^{\circ} \mathrm{C}$ and $5 \% \mathrm{CO}_{2}$ for at least 14 days before surgical inoculation. On the day of surgery, cells were harvested with $0.05-0.1 \%$ trypsin-EDTA (Gibco, Life Technologies, Paisley, UK) and resuspended in phosphate buffered saline (PBS) or Hank's Balanced Salt Solution (HBSS). MRMT-1 cells (Rikken Cell Bank, Ibaraki, Japan), transfected with Luc2 as previously described [62], were cultured in the same fashion. Unless otherwise specified, all cell reagents were purchased from Invitrogen, Nærum, Denmark. 


\subsection{Animals}

Five- to 12-week-old male and female Sprague Dawley rats (Taconic Biosciences, Tornbjerg, Denmark) were housed in groups of four or five in standard, individually ventilated cages (Naxgen Rat 1800, floor area: $1805 \mathrm{~cm}^{2}$, Herfølge, Denmark) in a specific pathogen-free facility at a 12-h light/dark cycle (light on at 7:00 a.m.), with normal bedding (Tapvei 2HV, Tapvei, Estonia) and ad libitum access to water and food (Altromin 1314, Brogaarden, Denmark). Environmental enrichment was provided as red translucent shelters, gnawing sticks, and nesting material (Tapvei, Estonia). Animal experiments were approved by the Danish Animal Experiments Inspectorate (Copenhagen, Denmark), ethical code: 2014-15-0201-00031, and complied with the Danish Act on Animal Experiments (LBK No. 474 of 15/05/2014) and with the Animal Research: Reporting of In Vivo Experiments (ARRIVE) guidelines for reporting animal experimentation. All efforts were made to minimize animal suffering. All animals were used in a single experiment and were drug/test naïve prior to the initiation of the experiment. Welfare assessments (including observation of weight, presence of porphyrin, fur condition, food/water intake, stools, and development of abnormal behaviors) were conducted regularly throughout the experimental time. A total of 87 rats were included in the cancer experiments and 25 in the SNI studies. For the cancer studies, 28 rats were excluded due to lack of cancer development $(n=26)$, growth of extraosseous tumor $(n=1)$, or bad perfusions $(n=1)$. SNI-operated rats that failed to show mechanical hyperalgesia $(n=1)$ or sham-operated rats showing hyperalgesia $(n=2)$, as measured in the von Frey test, were excluded from the study.

\subsection{CIBP Surgery}

CIBP surgeries were conducted under isoflurane anesthesia (3-4\% for induction, $2-2.5 \%$ for maintenance; Nomeco or Baxter, Søborg, Denmark). Carprofen (5 mg/kg, subcutaneous (s.c.), Norodyl, Pfizer, Denmark) was administered before surgery for post-surgical analgesia. Intratibial inoculation of cancer cells was conducted, as previously described [17,63]. The medial distal side of the right hind limb was shaved and disinfected with $70 \%$ ethanol and an incision of approximately $1 \mathrm{~cm}$ was pierced in the skin with a scalpel. The tibia was exposed and a $0.7-\mathrm{mm}$ dental drill was used to drill a hole toward the proximal intramedullary cavity of the tibia, in which a catheter (Smiths Medical, Ashford, UK) was inserted and $10 \mu \mathrm{L}$ of the cancer cell suspension or vehicle was inoculated. Walker 256 cells were injected in a concentration of $10^{5}$ cells/10 $\mu \mathrm{L}$ except for the comparison study (comparing MRMT-1-inoculated rats and Walker 256-inoculated rats), in which both MRMT- 1 and Walker 256 cells were injected in a concentration of $5 \times 10^{3}$ cells $/ 10 \mu \mathrm{L}$. The hole was closed with restorative cement (IRM cement, Dentsply, Denmark), the wound profusely irrigated with saline, and the skin sealed with two metal clips $(11 \times 2.5 \mathrm{~cm}$, Agnthos, Sweden). Xylocaine gel $(2 \% w / v$; AstraZeneca, Copenhagen, Denmark) was applied on the surgical site. Clips were removed approximately $4-7$ days post-surgery. Animals were stratified into cancer-bearing or sham groups according to weight.

\subsection{Spared Nerve Injury (SNI) Surgery}

SNI surgeries were conducted under isoflurane (3-4\% for induction, $2-2.5 \%$ for maintenance; Baxter A/S, Søborg, Denmark) or a 1:1 Hypnorm:Dormicum cocktail (fentanyl $0.630 \mathrm{mg} / \mathrm{kg}$ fluanisone $20 \mathrm{mg} / \mathrm{kg}$ and midazolam $10 \mathrm{mg} / \mathrm{kg}$, VetaPharma, Hvidovre, Denmark and Accord, Denmark) in sterile water and injected s.c. Carprofen $(5 \mathrm{mg} / \mathrm{kg}$, s.c., Norodyl, Pfizer, Denmark) was administered before surgery and 24 and $48 \mathrm{~h}$ after to control post-surgical pain. Upon anesthesia, the posterior side of the right hind limb was shaved and disinfected with $70 \%$ ethanol. Using a scalpel, an incision of approximately $1 \mathrm{~cm}$ was pierced in the skin and a scissor was used to make a separation of the biceps femoris muscle, exposing the three branches of the sciatic nerve. Ensuring that the sural nerve branch was untouched, the tibial and peritoneal nerves were tightly ligated with 4.0 non-absorbable silk suture (Perma Hand, Ethicon, Brøndby, Denmark) and 2-3 mm of the nerve excised to prevent nerve regeneration. Sham animals underwent a similar procedure without ligation or excision of 
any nerve branches. Muscle and skin were then sutured (3-0 Vicryl polyglactin, absorbable thread, Ethicon, Brøndby, Denmark) and glued (Vetbond, 3M, Kruuse, Langeskov, Denmark), and xylocaine gel ( $2 \% w / v$; AstraZeneca, Copenhagen, Denmark) was applied to the surgical wound. Animals were stratified according to baseline paw withdrawal threshold into sham or SNI.

\subsection{Drug Interventions}

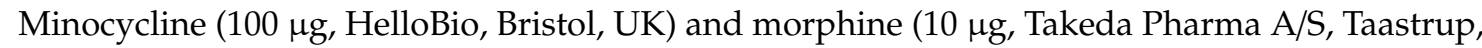
Denmark) were prepared fresh on the day of injection; osmolarity and $\mathrm{pH}$ were measured and adjusted to $294 \mathrm{osmol} / \mathrm{kg}$ and $\mathrm{pH} \mathrm{7,} \mathrm{respectively.} \mathrm{Saline} \mathrm{was} \mathrm{used} \mathrm{as} \mathrm{vehicle.} \mathrm{Rats} \mathrm{were} \mathrm{randomized} \mathrm{to}$ receive drug or vehicle. Drugs were administered by a different researcher than the one conducting behavioral testing to ensure complete blinding throughout the experiment. All drugs were intrathecally administered through lumbar puncture in a volume of $10 \mu \mathrm{L}$. Briefly, rats were anesthetized with isoflurane (4-5\% for induction, 1.5-2\% for maintenance, Baxter, Denmark) and the back was shaved and disinfected. A 23 gauge needle attached to a Hamilton syringe was inserted at the level of the lumbar segment L5-L6. Needle placement was confirmed by flinching of a hind limb or tail. One rat showed signs of motor impairment following intrathecal injection that lasted about $60 \mathrm{~min}$; this was probably due to spinal damage during lumbar puncture and the animal was excluded from analyses. No other adverse effects were observed in any of the other experimental groups.

\subsection{Behavioral Tests}

All behavioral testing was conducted during the light phase (7:00 a.m. to 7:00 p.m.). Within each experiment, behavioral tests were performed by the same researcher, blinded to experimental groups and treatment.

\subsubsection{Limb Use}

The limb-use test was used to assess the gait of cancer-bearing and sham animals. Rats were placed in groups in a transparent plastic cage $(650 \times 250 \times 200 \mathrm{~mm})$ and left to acclimatize for $10 \mathrm{~min}$. Thereafter, rats were individually observed for three minutes and scored as follows: $3=$ normal gait, 2 = insignificant limping, 1 = significant limping and shift in bodyweight distribution toward the healthy limb, $0=$ lack of use of ipsilateral limb. A limb-use score of 0 was set as humane endpoint.

\subsubsection{Weight Bearing}

The weight-bearing test was used to assess the bodyweight distribution of cancer-bearing and sham animals. Rats were individually placed in an Incapacitance Tester (MJS Technology Ltd., Buntingford, Hertfordshire, UK) consisting of two separate scales measuring the individual load on each hind limb. The amount of weight placed on the hind limbs for four seconds was measured three times for each animal. The weight-bearing ratio was calculated as average weight placed on the ipsilateral limb divided by the total average weight placed on both hind limbs.

\subsubsection{Von Frey}

Mechanical hypersensitivity of SNI-operated and sham animals was measured with von Frey monofilaments (North Coast Touch Test, CA, USA) following the Dixon up-down method [64]. Briefly, rats were placed in individual cages on an elevated mesh floor and allowed to acclimatize for at least $30 \mathrm{~min}$. Rats were not tested while grooming or sleeping. Starting at $2.0 \mathrm{~g}$, von Frey monofilaments $(0.40-15.0 \mathrm{~g})$ were sequentially applied to the right outer plantar area of the ipsilateral hind limb for $2-3 \mathrm{~s}$. A positive response was followed by the application of a weaker filament, while a negative response was followed by the application of a stronger filament. Positive responses were defined as withdrawal, stamping, or shaking the paw in three out of five applications of the same monofilament. 
The resulting pattern of positive and negative responses was used to calculate the 50\% Paw Withdrawal Threshold (PWT) as defined by Dixon [64].

\subsection{X-ray Imaging}

The relative bone density of the ipsilateral tibia of cancer-bearing and sham rats was evaluated through X-ray imaging, as previously described [62]. Briefly, rats were anesthetized with isoflurane (3-4\% for induction, 2-3\% for maintenance, Nomeco or Baxter, Denmark) and placed in a Lumina XR Apparatus (Caliper Life Science, Teralgene, Belgium). X-ray images of the tibia were captured and calibrated to a standard aluminum wedge. Image analyses was conducted in Image J (National Institute of Health, Madison, Wisconsin, USA) by measuring the grayscale value of the distal tibial area and subtracting the mean grayscale value of two soft-tissue regions; the final value was then normalized against the standard aluminum wedge. X-ray images were analyzed by a researcher blinded to the experimental groups and treatment.

\subsection{Tissue Extraction}

Rats were deeply anesthetized through s.c. administration of a 3:4 Ketaminol/Dexdormitor cocktail (Ketaminol, MSD Animal Health, Copenhagen, Denmark; Dexdormitor, Orion Pharma, Copenhagen, Denmark; s.c. injection of $1.75 \mathrm{~mL} / \mathrm{kg}$ ) or a 1:1 Hypnorm:Dormicum cocktail (fentanyl $0.630 \mathrm{mg} / \mathrm{kg}$, fluanisone $20 \mathrm{mg} / \mathrm{kg}$, and midazolam $10 \mathrm{mg} / \mathrm{kg}$, VetaPharma, Hvidovre, Denmark and Accord, Denmark) in sterile water and injected s.c. The abdominal cavity was cut open, the diaphragm punctured, and the thoracic cage cut to expose the heart. A 23-G needle connected to a MasterFleex L/S pump (Buch \& Holm, Herlev, Denmark) was inserted into the left ventricle of the heart and the right atrium was cut open. Following PBS perfusion, a flow of ice-cold 4\% paraformaldehyde (PFA) with $0.12 \%$ picric acid (VWR, Leicestershire, UK) was applied. The lumbar region of the spinal cord was extracted and post-fixated overnight in $4 \%$ PFA with $0.12 \%$ picric acid at $4{ }^{\circ} \mathrm{C}$. Tissue was dehydrated in $30 \%$ sucrose at $4{ }^{\circ} \mathrm{C}$, embedded in Tissue-Tek O.C.T. compound (Sakura, Japan), and stored at $-80{ }^{\circ} \mathrm{C}$ until further analyses.

\subsection{Immunohistochemistry}

L3-L4 spinal cord segments were serially sectioned on a cryostat (Leica CM 3050 S; Leica Microsystems A/S, Herlev, Denmark) and thaw mounted onto SuperFrost plus microscope slides (Menzel Glazer; VWR, Denmark). Sections were $30 \mu \mathrm{m}$ thick and collected at a distance of $240 \mu \mathrm{m}$. Sections were washed $3 \times 5 \mathrm{~min}$ in phosphate-buffered saline (PBS) and $1 \times 5 \mathrm{~min}$ in $0.1 \%$ Triton X-100 in PBS (T-PBS) to remove Tissue-Tek O.C.T. compound. For double immunostaining, sections were blocked for $1 \mathrm{~h}$ in 5\% donkey serum (Jackson ImmunoResearch, Cambridgeshire, UK) in T-PBS at room temperature (RT), washed $3 \times 5 \mathrm{~min}$ in T-PBS, and incubated overnight at $4{ }^{\circ} \mathrm{C}$ with rabbit phospho-p38 MAPK (Thr180/Tyr182) monoclonal antibody (1:500, Bionordika, Cell Signaling Technology 4511S, Herlev, Denmark). The following day sections were washed $3 \times 5 \mathrm{~min}$ in PBS and incubated overnight at $4{ }^{\circ} \mathrm{C}$ with goat anti-Iba-1 polyclonal antibody (1:1000, Abcam ab107159, Cambridge, UK). On the third day, sections were washed $3 \times 5$ min in PBS, incubated two hours at RT with donkey anti-rabbit Alexa Flour 594 (1:300, Fisher Scientific 10798994, Slangerup, Denmark), washed $4 \times 5$ min in PBS, incubated two hours at RT with donkey anti-goat Alexa Flour 488 (1:1000, Fisher Scientific 10246392, Slangerup, Denmark), washed $3 \times 5$ min with PBS, and counterstained with DAPI (1:30,000, FluoroPure, Thermo Scientific, Eugene, OR, USA). After a final $3 \times 5$ min wash in PBS, sections were mounted with Dako fluorescence mounting medium (Agilent Technologies Denmark ApS, Glostrup, Denmark) and cover slipped. Single immunostaining for Iba-1 was performed similarly using $1 \%$ goat-serum (Jackson ImmunoResearch Europe Ltd., Cambridgeshire, UK) in T-PBS, rabbit anti-Iba-1 antibody (1:1000, Wako Pure Chemical Industries, Ltd., Neuss, Germany), and goat anti-rabbit Alexa Flour 594 (1:000, Thermo Fisher Scientific A-11012, Slangerup, Denmark). Unspecific staining of secondary 
antibodies and background fluorescence were investigated by the omission of primary or secondary antibodies. No staining for Iba-1 or P-p38 was observed.

\subsection{Image Analyses}

Images were acquired using a Zeiss Axioskop2 microscope (Zeiss, Feldbach, Switzerland) equipped with an Axiocam MRm camera (HAL100) (Zeiss, Feldbach, Switzerland) and a fluorescent Transmitter (HXP 120, Digital Scientific, Cambridge, UK). Images from single and double immunostainings were acquired with $20 \times$ and $40 \times$ objectives, respectively. Image analysis was performed in Image J (Wayne Rasband; National Institutes of Health, Bethesda, MD, USA) using image overlay. Numbers of Iba-1 positive $\left(\mathrm{Iba}-\mathrm{1}^{+}\right)$and $\mathrm{P}-\mathrm{p} 38^{+}$cells were for double immunostaining quantified in a predetermined area of $347 \times 260 \mu^{2}$, placed in the medial part of the gray matter, and aligned with the dorsal edge of the gray matter to include parts of laminae I-IV of the ipsilateral or contralateral dorsal horn (Figure 2A). For single immunostaining, the total gray matter covering laminae I-IV was outlined and the numbers of Iba- $1^{+}$cells quantified. A cell was only counted if it displayed an obvious nucleus, as judged by DAPI stain. From each rat, three of the collected sections were randomly chosen to cover a longitudinal distance of minimum $580 \mu \mathrm{m}$ and maximum $1200 \mu \mathrm{m}$, the numbers of Iba- $1^{+}$and P-p38 $8^{+}$cells counted, and the average number of cells included in the statistical analysis. The results are presented as cells per an area of $347 \times 260 \mu \mathrm{m}^{2}$.

Point scanning confocal microscopy was performed with a Leica SP5-X MP system (Leica Microsystems, Heidelberg, Germany) equipped with a 405-nm diode laser and a fast beamsplitter for excitation of DAPI, a white light laser for excitation of Alexa fluorophores, and a tunable acousto-optical beamsplitter. A sensitive hybrid pixel detector (HyD) was used for Alexa Flour 488, and standard photon multiplier tubes were used for the other laser lines. Images were acquired with LAS AF software (Leica) using a $40 \times$ objective with 1.3 magnification oil immersion. For determination of co-localization of P-p38 ${ }^{+}$cells with Iba- $1^{+}$cells, cells were quantified in a predetermined area of $450 \times 338 \mu \mathrm{m}^{2}$, aligned with the medial and dorsal edge of the ipsilateral dorsal horn gray matter covering most parts of laminae I-IV. Three SNI-operated rats were included in the analysis and a single L4 section counted from each rat. Cells that were positive for both P-p38 and DAPI were included as P-p38 ${ }^{+}$, while cells that were positive for P-p38, DAPI, and Iba1 were included as co-localized with microglia.

\subsection{Statistical Analyses}

All data were analyzed in GraphPad Prism 8.0 (GraphPad Software, San Diego, CA, USA) or SAS (SAS Institute Inc., Cary, NC, USA) and all graphs were plotted in GraphPad Prism 8.0. Power calculations were performed in $G^{*}$ Power v3.1.9.7 [65]. Effect size was estimated on the basis of the number of Iba- 1 cells in the ipsilateral dorsal horn of sham and SNI-operated rats. Considering effect size $d=4.22, \alpha=0.05$, and a power of 0.95 , the estimated sample size was $\mathrm{n}=3$. All immunohistological data and parametric behavioral data were analyzed by two-way ANOVA (repeated measures for behavioral data) followed by Sidak's post hoc test for multiple comparisons. Nonparametric behavioral data were analyzed by Friedman's two-way test and Wilcoxon's two-sample test for single time points. In the pharmacology study, nonparametric data were analyzed by one-way ANOVA followed by Dunnett's test for multiple comparisons at single time points. Single animals were defined as experimental units, and sample size was empirically determined from pilot studies. All data are presented as mean \pm SEM.

\subsection{Data Sharing Statement}

All data and protocols generated during the studies described in this manuscript are freely available upon reasonable request. 


\section{Conclusions}

Here we demonstrated that microglial reaction is not a main feature of either the Walker 256 or MRMT-1 model of CIBP, independent of disease stage or sex of the rat. In accordance, minocycline failed to attenuate pain-like behaviors in cancer-bearing male rats. This finding adds to the debate that even within the same models of CIBP significant variations are seen in disease features that are considered possible drug targets. However, instead of dismissing the translational validity of the models, we suggest that these diverse features may actually reflect the heterogeneity of the patient population. Thus, further characterization of the models is crucial to understand, and perhaps increase, their translational validity.

Supplementary Materials: The following are available online at http://www.mdpi.com/2072-6694/12/10/2740/s1, Figure S1: Development of nociception and osteolytic bone degradation in Sprague Dawley rats inoculated with Walker 256 or MRMT-1 cancer cells; Figure S2: Development of nociception and osteolytic bone degradation in male Sprague Dawley rats following Walker 256 cancer cell inoculation.

Author Contributions: Conceptualization, M.D.-d., R.B.H., C.K.A., and A.-M.H.; methodology, M.D.-d., R.B.H., C.K.A., L.N., S.N.N., K.K., and L.M.D.; validation, R.B.A.; formal analysis, R.B.H. and M.D.-d.; investigation, M.D.-d., R.B.H., C.K.A., L.N., S.N.N., K.K., L.M.D., and R.B.A.; writing-original draft preparation, M.D.-d. and R.B.H.; writing-review and editing, M.D.-d. and A.-M.H.; supervision, A.-M.H.; project administration, M.D.-d., R.B.H., and A.-M.H.; funding acquisition, M.D.-d., R.B.H., and A.-M.H. All authors have read and agreed to the published version of the manuscript.

Funding: This project was funded by the European Union's Horizon 2020 research and innovation program under the Marie Skłodowska-Curie grant agreement No. 642720 (A.-M.H., M.D.-d.), IMK Almene Foundation (A.-M.H., M.D.-d.), Advokat Bent Thorbergs Fond (A.-M.H., R.B.H.), and Novo Nordisk Foundation, grant NNF17OC0029620 (A.-M.H., R.B.H.).

Acknowledgments: The authors thank Camilla S. Dall for technical support.

Conflicts of Interest: The authors declare no conflict of interest. The funders had no role in the design of the study; in the collection, analyses, or interpretation of data; in the writing of the manuscript; or in the decision to publish the results.

\section{References}

1. Breivik, H.; Cherny, N.; Collett, B.; De Conno, F.; Filbet, M.; Foubert, A.J.; Cohen, R.; Dow, L. Cancer-related pain: A pan-European survey of prevalence, treatment, and patient attitudes. Ann. Oncol. 2009, 20, 1420-1433. [CrossRef] [PubMed]

2. Grond, S.; Zech, D.; Diefenbach, C.; Radbruch, L.; Lehmann, K.A. Assessment of cancer pain: A prospective evaluation in 2266 cancer patients referred to a pain service. Pain 1996, 64, 107-114. [CrossRef] [PubMed]

3. Mercadante, S. Malignant bone pain: Pathophysiology and treatment. Pain 1997, 69, 1-18. [CrossRef] [PubMed]

4. Banning, A.; Sjøgren, P.; Henriksen, H. Treatment outcome in a multidisciplinary cancer pain clinic. Pain 1991, 47, 129-134. [CrossRef] [PubMed]

5. Caraceni, A.; Brunelli, C.; Zecca, E.; Portenoy, R.K. Breakthrough pain characteristics and syndromes in patients with cancer pain. An international survey. Palliat. Med. 2004, 18, 177-183. [CrossRef]

6. Laird, B.J.; Walley, J.D.; Murray, G.; Clausen, E.; Colvin, L.A.; Fallon, M. Characterization of cancer-induced bone pain: An exploratory study. Support. Care Cancer 2010, 19, 1393-1401. [CrossRef]

7. Kurita, G.P.; Tange, U.B.; Farholt, H.; Sonne, N.M.; Strömgren, A.S.; Ankersen, L.; Kristensen, L.; Bendixen, L.; Groenvold, M.; Petersen, M.A.; et al. Pain characteristics and management of inpatients admitted to a comprehensive cancer centre: A cross-sectional study. Acta Anaesthesiol. Scand. 2013, 57, 518-525. [CrossRef]

8. Van den Beuken-van Everdingen, M.H.J.; Hochstenbach, L.M.; Joosten, E.A.; Tjan-Heijnen, V.C.; Janssen, D.J.; Joosten, B.E. Update on Prevalence of Pain in Patients With Cancer: Systematic Review and Meta-Analysis. J. Pain Symptom Manag. 2016, 51, 1070-1090.e9. [CrossRef]

9. Jimenez-Andrade, J.M.; Mantyh, W.G.; Bloom, A.P.; Ferng, A.S.; Geffre, C.P.; Mantyh, P.W. Bone cancer pain. Ann. N. Y. Acad. Sci. 2010, 1198, 173-181. [CrossRef]

10. Ibrahim, T.; Mercatali, L.; Amadori, D. Bone and cancer: The osteoncology. Clin. Cases Miner. Bone Metab. 2013, 10, 121-123. 
11. Yekkirala, A.S.; Roberson, D.P.; Bean, B.P.; Woolf, C.J. Breaking barriers to novel analgesic drug development. Nat. Rev. Drug Discov. 2017, 16, 545-564. [CrossRef]

12. Hansen, R.B.; Frost, C.Ø.; Sonne, N.M.; Johnsen, A.T.; Heegaard, A.-M. Exploring the Patients' Perception of Background and Breakthrough Pain: A McGill Pain Questionnaire Inquiry in Patients with Bone Cancer Pain. J. Palliat. Med. 2019, 22, 881-883. [CrossRef]

13. Whiteside, G.; Adedoyin, A.; Leventhal, L. Predictive validity of animal pain models? A comparison of the pharmacokinetic-pharmacodynamic relationship for pain drugs in rats and humans. Neuropharmacology 2008, 54, 767-775. [CrossRef]

14. King, T.; Porreca, F. Preclinical Assessment of Pain: Improving Models in Discovery Research. In Neuroinflammation and Schizophrenia; Springer Science and Business Media LLC.: Berlin/Heidelberg, Germany, 2014; Volume 20, pp. 101-120.

15. Schwei, M.J.; Honore, P.; Rogers, S.D.; Salak-Johnson, J.L.; Finke, M.P.; Ramnaraine, M.L.; Clohisy, D.R.; Mantyh, P.W. Neurochemical and Cellular Reorganization of the Spinal Cord in a Murine Model of Bone Cancer Pain. J. Neurosci. 1999, 19, 10886-10897. [CrossRef]

16. Mao-Ying, Q.-L.; Zhao, J.; Dong, Z.-Q.; Wang, J.; Yu, J.; Yan, M.-F.; Zhang, Y.-Q.; Wu, G.-C.; Wang, Y.-Q. A rat model of bone cancer pain induced by intra-tibia inoculation of Walker 256 mammary gland carcinoma cells. Biochem. Biophys. Res. Commun. 2006, 345, 1292-1298. [CrossRef]

17. Medhurst, S.J.; Walker, K.; Bowes, M.; Kidd, B.L.; Glatt, M.; Muller, M.; Hattenberger, M.; Vaxelaire, J.; O'reilly, T.; Wotherspoon, G.; et al. A rat model of bone cancer pain. Pain 2002, 96, 129-140. [CrossRef]

18. Falk, S.; Dickenson, A.H. Pain and Nociception: Mechanisms of Cancer-Induced Bone Pain. J. Clin. Oncol. 2014, 32, 1647-1654. [CrossRef]

19. Honore, P.; Mantyh, P.W. Bone Cancer Pain: From Mechanism to Model to Therapy. Pain Med. 2000, 1, 303-309. [CrossRef]

20. Honore, P.; Rogers, S.D.; Schwei, M.J.; Salak-Johnson, J.L.; Luger, N.M.; Sabino, M.C.; Clohisy, D.R.; Mantyh, P.W. Murine models of inflammatory, neuropathic and cancer pain each generates a unique set of neurochemical changes in the spinal cord and sensory neurons. Neuroscience 2000, 98, 585-598. [CrossRef]

21. Gilmore, S.A. Proliferation of non-neuronal cells in spinal cords of irradiated, immature rats following transection of the sciatic nerve. Anat. Rec. 1975, 181, 799-811. [CrossRef]

22. Colonna, M.; Butovsky, O. Microglia Function in the Central Nervous System During Health and Neurodegeneration. Annu. Rev. Immunol. 2017, 35, 441-468. [CrossRef]

23. Inoue, K.; Tsuda, M. Microglia in neuropathic pain: Cellular and molecular mechanisms and therapeutic potential. Nat. Rev. Neurosci. 2018, 19, 138-152. [CrossRef]

24. Zhao, H.; Alam, A.; Chen, Q.; Eusman, M.A.; Pal, A.; Eguchi, S.; Wu, L.; Ma, D. The role of microglia in the pathobiology of neuropathic pain development: What do we know? Br. J. Anaesth. 2017, 118, 504-516. [CrossRef]

25. Chen, G.; Yu-Qiu, Z.; Qadri, Y.; Serhan, C.N.; Ji, R.-R. Microglia in Pain: Detrimental and Protective Roles in Pathogenesis and Resolution of Pain. Neuron 2018, 100, 1292-1311. [CrossRef]

26. Wang, L.-N.; Yao, M.; Yang, J.-P.; Peng, J.; Peng, Y.; Li, C.-F.; Zhang, Y.-B.; Ji, F.; Cheng, H.; Xu, Q.-N.; et al. Cancer-induced bone pain sequentially activates the ERK/MAPK pathway in different cell types in the rat spinal cord. Mol. Pain 2011, 7, 48. [CrossRef]

27. Sorge, R.E.; Mapplebeck, J.C.S.; Rosen, S.; Beggs, S.; Taves, S.; Alexander, J.K.; Martin, L.J.; Austin, J.-S.; Sotocinal, S.G.; Chen, D.; et al. Different immune cells mediate mechanical pain hypersensitivity in male and female mice. Nat. Neurosci. 2015, 18, 1081-1083. [CrossRef]

28. Huang, L.; Gao, Y.-J.; Wang, J.; Strichartz, G. Shifts in Cell-type Expression Accompany a Diminishing Role of Spinal P38-Mapkinase Activation over Time during Prolonged Postoperative Pain. Anesthesiology 2011, 115, 1281-1290. [CrossRef]

29. Mapplebeck, J.C.S.; Beggs, S.; Salter, M.W. Sex differences in pain. Pain 2016, 157, S2-S6. [CrossRef]

30. Yang, Y.; Li, H.; Li, T.-T.; Luo, H.; Gu, X.-Y.; Lu, N.; Ji, R.-R.; Yu-Qiu, Z. Delayed Activation of Spinal Microglia Contributes to the Maintenance of Bone Cancer Pain in Female Wistar Rats via P2X7 Receptor and IL-18. J. Neurosci. 2015, 35, 7950-7963. [CrossRef]

31. Lan, L.S.; Yang, J.-P.; Na, W.L.; Miao, J.; Qiu, Q.-C.; Ma, Z.; Lei, L.; Li, C.-F.; Ren, C.; Jin, Z.; et al. Down-regulation of Toll-like receptor 4 gene expression by short interfering RNA attenuates bone cancer pain in a rat model. Mol. Pain 2010, 6, 2. [CrossRef] 
32. Lu, C.; Liu, Y.; Sun, B.; Sun, Y.; Hou, B.; Zhang, Y.; Ma, Z.; Gu, X. Intrathecal Injection of JWH-015 Attenuates Bone Cancer Pain Via Time-Dependent Modification of Pro-inflammatory Cytokines Expression and Astrocytes Activity in Spinal Cord. Inflammation 2015, 38, 1880-1890. [CrossRef]

33. Cecchini, M.G.; Wetterwald, A.; Van Der Pluijm, G.; Thalmann, G.N. Molecular and Biological Mechanisms of Bone Metastasis. EAU Updat. Ser. 2005, 3, 214-226. [CrossRef]

34. Hald, A.; Nedergaard, S.; Hansen, R.R.; Ding, M.; Heegaard, A.-M. Differential activation of spinal cord glial cells in murine models of neuropathic and cancer pain. Eur. J. Pain 2009, 13, 138-145. [CrossRef]

35. Ducourneau, V.R.; Dolique, T.; Hachem-Delaunay, S.; Miraucourt, L.S.; Amadio, A.; Blaszczyk, L.; Jacquot, F.; Ly, J.; Devoize, L.; Oliet, S.H.; et al. Cancer pain is not necessarily correlated with spinal overexpression of reactive glia markers. Pain 2014, 155, 275-291. [CrossRef]

36. Dore-Savard, L.; Otis, V.; Belleville, K.; Lemire, M.; Archambault, M.; Tremblay, L.; Beaudoin, J.-F.; Beaudet, N.; LeComte, R.; Lepage, M.; et al. Behavioral, Medical Imaging and Histopathological Features of a New Rat Model of Bone Cancer Pain. PLoS ONE 2010, 5, e13774. [CrossRef]

37. Cao, F.; Gao, F.; Xu, A.-J.; Chen, Z.-J.; Chen, S.-S.; Yang, H.; Yu, H.-H.; Mei, W.; Liu, X.-J.; Xiao, X.-P.; et al. Regulation of spinal neuroimmune responses by prolonged morphine treatment in a rat model of cancer induced bone pain. Brain Res. 2010, 1326, 162-173. [CrossRef]

38. Svensson, C.I.; Marsala, M.; Westerlund, A.; Calcutt, N.A.; Campana, W.M.; Freshwater, J.D.; Catalano, R.; Feng, Y.; Protter, A.A.; Scott, B.; et al. Activation of p38 mitogen-activated protein kinase in spinal microglia is a critical link in inflammation-induced spinal pain processing. J. Neurochem. 2003, 86, 1534-1544. [CrossRef]

39. Jin, S.-X.; Zhuang, Z.-Y.; Woolf, C.J.; Ji, R.-R. p38 Mitogen-Activated Protein Kinase Is Activated after a Spinal Nerve Ligation in Spinal Cord Microglia and Dorsal Root Ganglion Neurons and Contributes to the Generation of Neuropathic Pain. J. Neurosci. 2003, 23, 4017-4022. [CrossRef]

40. Tsuda, M.; Mizokoshi, A.; Shigemoto-Mogami, Y.; Koizumi, S.; Inoue, K. Activation of p38 mitogen-activated protein kinase in spinal hyperactive microglia contributes to pain hypersensitivity following peripheral nerve injury. Glia 2003, 45, 89-95. [CrossRef]

41. Wang, Z.; Ma, W.; Chabot, J.-G.; Quirion, R. Cell-type specific activation of p38 and ERK mediates calcitonin gene-related peptide involvement in tolerance to morphine-induced analgesia. FASEB J. 2009, 23, 2576-2586. [CrossRef]

42. Clark, A.K.; Staniland, A.A.; Marchand, F.; Kaan, T.K.Y.; McMahon, S.B.; Malcangio, M. P2X7-dependent release of interleukin-1beta and nociception in the spinal cord following lipopolysaccharide. J. Neurosci. 2010, 30, 573-582. [CrossRef]

43. Ji, R.-R.; Berta, T.; Nedergaard, M. Glia and pain: Is chronic pain a gliopathy? Pain 2013, 154, S10-S28. [CrossRef]

44. Song, H.; Han, Y.; Pan, C.; Deng, X.; Dai, W.; Hu, L.; Jiang, C.; Yang, Y.; Cheng, Z.; Li, F.; et al. Activation of Adenosine Monophosphate-activated Protein Kinase Suppresses Neuroinflammation and Ameliorates Bone Cancer Pain. Anesthesiology 2015, 123, 1170-1185. [CrossRef] [PubMed]

45. Zhuang, Z.-Y.; Wen, Y.R.; Zhang, D.-R.; Borsello, T.; Bonny, C.; Strichartz, G.R.; Decosterd, I.; Ji, R.-R. A Peptide c-Jun N-Terminal Kinase (JNK) Inhibitor Blocks Mechanical Allodynia after Spinal Nerve Ligation: Respective Roles of JNK Activation in Primary Sensory Neurons and Spinal Astrocytes for Neuropathic Pain Development and Maintenance. J. Neurosci. 2006, 26, 3551-3560. [CrossRef] [PubMed]

46. Mao-Ying, Q.-L.; Wang, X.-W.; Yang, C.-J.; Li, X.; Mi, W.-L.; Wu, G.-C.; Wang, Y.-Q. Robust spinal neuroinflammation mediates mechanical allodynia in Walker 256 induced bone cancer rats. Mol. Brain 2012, 5, 16. [CrossRef] [PubMed]

47. Fan, H.-B.; Zhang, T.; Sun, K.; Song, S.-P.; Cao, S.-B.; Zhang, H.; Shen, W. Corticotropin-releasing factor mediates bone cancer induced pain through neuronal activation in rat spinal cord. Tumor Biol. 2015, 36, 9559-9565. [CrossRef]

48. Hu, J.-H.; Yang, J.; Liu, L.; Li, C.-F.; Wang, L.-N.; Ji, F.-H.; Cheng, H. Involvement of CX3CR1 in bone cancer pain through the activation of microglia p38 MAPK pathway in the spinal cord. Brain Res. 2012, 1465, 1-9. [CrossRef]

49. Jin, X.-H.; Wang, L.-N.; Zuo, J.-L.; Yang, J.-P.; Liu, S.-L. P2X4 receptor in the dorsal horn partially contributes to brain-derived neurotrophic factor oversecretion and toll-like receptor-4 receptor activation associated with bone cancer pain. J. Neurosci. Res. 2014, 92, 1690-1702. [CrossRef] 
50. Wang, L.-N.; Yang, J.-P.; Zhan, Y.; Ji, F.-H.; Wang, X.-Y.; Zuo, J.-L.; Xu, Q.-N. Minocycline-induced reduction of brain-derived neurotrophic factor expression in relation to cancer-induced bone pain in rats. J. Neurosci. Res. 2011, 90, 672-681. [CrossRef]

51. Zhang, R.-X.; Liu, B.; Wang, L.; Ren, K.; Qiao, J.-T.; Berman, B.M.; Lao, L. Spinal glial activation in a new rat model of bone cancer pain produced by prostate cancer cell inoculation of the tibia. Pain 2005, 118, 125-136. [CrossRef]

52. Lewis, K.; Harford-Wright, E.; Vink, R.; Ghabriel, M.N. Characterisation of Walker 256 breast carcinoma cells from two tumour cell banks as assessed using two models of secondary brain tumours. Cancer Cell Int. 2013, 13, 5. [CrossRef] [PubMed]

53. Kristensen, P.; Heegaard, A.-M.; Hestehave, S.; Jeggo, R.; Bjerrum, O.J.; Munro, G. Vendor-derived differences in injury-induced pain phenotype and pharmacology of Sprague-Dawley rats: Does it matter? Eur. J. Pain 2016, 21, 692-704. [CrossRef] [PubMed]

54. Blackburn-Munro, G. Pain-like behaviours in animals-How human are they? Trends Pharmacol. Sci. 2004, 25, 299-305. [CrossRef] [PubMed]

55. Currie, G.L.; Delaney, A.; Bennett, M.I.; Dickenson, A.H.; Egan, K.J.; Vesterinen, H.M.; Sena, E.S.; MacLeod, M.; Colvin, L.A.; Fallon, M. Animal models of bone cancer pain: Systematic review and meta-analyses. Pain 2013, 154, 917-926. [CrossRef] [PubMed]

56. Delaney, A.; Fleetwood-Walker, S.M.; Colvin, L.A.; Fallon, M. Translational medicine: Cancer pain mechanisms and management. Br. J. Anaesth. 2008, 101, 87-94. [CrossRef]

57. Kong, X.; Wei, J.; Wang, D.; Zhu, X.; Zhou, Y.; Wang, S.; Xu, G.-Y.; Jiang, G. Upregulation of Spinal Voltage-Dependent Anion Channel 1 Contributes to Bone Cancer Pain Hypersensitivity in Rats. Neurosci. Bull. 2017, 33, 711-721. [CrossRef]

58. Martinez, V.; Szekely, B.; Lemarie, J.; Martin, F.; Gentili, M.; Ben Ammar, S.; Lepeintre, J.F.; De Loubresse, C.G.; Chauvin, M.; Bouhassira, D.; et al. The efficacy of a glial inhibitor, minocycline, for preventing persistent pain after lumbar discectomy: A randomized, double-blind, controlled study. Pain 2013, 154, 1197-1203. [CrossRef]

59. Vanelderen, P.; Van Zundert, J.; Kozicz, T.; Puylaert, M.; De Vooght, P.; Mestrum, R.; Heylen, R.; Roubos, E.; Vissers, K. Effect of Minocycline on Lumbar Radicular Neuropathic Pain. Anesthesiology 2015, 122, 399-406. [CrossRef]

60. Curtin, C.M.; Kenney, D.; Suarez, P.; Hentz, V.R.; Hernandez-Boussard, T.; Mackey, S.; Carroll, I.R. A Double-Blind Placebo Randomized Controlled Trial of Minocycline to Reduce Pain After Carpal Tunnel and Trigger Finger Release. J. Hand Surg. 2017, 42, 166-174. [CrossRef]

61. Sumitani, M.; Ueda, H.; Hozumi, J.; Inoue, R.; Kogure, T.; Ogata, T.; Yamada, Y. Minocycline Does Not Decrease Intensity of Neuropathic Pain, but Improves Its Affective Dimension. J. Pain Palliat. Care Pharmacother. 2015, 30. [CrossRef]

62. Falk, S.; Al-Dihaissy, T.; Mezzanotte, L.; Heegaard, A.-M. Effect of sex in the MRMT-1 model of cancer-induced bone pain. F1000Research 2015, 4, 445. [CrossRef] [PubMed]

63. Díaz-DelCastillo, M.; Christiansen, S.H.; Appel, C.K.; Falk, S.; Woldbye, D.P.; Heegaard, A.-M. Neuropeptide $\mathrm{Y}$ is Up-regulated and Induces Antinociception in Cancer-induced Bone Pain. Neuroscience 2018, 384, 111-119. [CrossRef] [PubMed]

64. Dixon, W.J. Efficient Analysis of Experimental Observations. Annu. Rev. Pharmacol. Toxicol. 1980, 20, 441-462. [CrossRef]

65. Faul, F.; Erdfelder, E.; Lang, A.-G.; Buchner, A. G*Power 3: A flexible statistical power analysis program for the social, behavioral, and biomedical sciences. Behav. Res. Methods 2007, 39, 175-191. [CrossRef] [PubMed]

(C) 2020 by the authors. Licensee MDPI, Basel, Switzerland. This article is an open access article distributed under the terms and conditions of the Creative Commons Attribution (CC BY) license (http://creativecommons.org/licenses/by/4.0/). 